\title{
Ensaio
}

\section{O que guardam as fotografias de família além de memórias?*}

What do family photographs hold besides memories?

Rodolfo Junqueira Fonseca**

* Recebido em: 21.03.2019. Aprovado em: 15.06.2019

** Doutorando em Sociologia PPGSOL - Unb. Diretor e produtor do filme documentário Até onde pode chegar um filme de família (2018). Email:

rodolfonjfonsecastudy@gmail.com

${ }^{1}$ Até pode chegar um filme de família (2018) combina uma telecinagem em Full HD inédita a partir do $35 \mathrm{~mm}$ do filme de família Reminiscências (1909-26), com imagens de arquivo, áudio, fotografias, material de imprensa e depoimentos com a participação ativa dos entrevistados na leitura e a interpretação dos acervos ao longo de todo o documentário, associadas a projeções urbanas e recursos do cinema de montagem para contar a biografia desconhecida de Aristides Junqueira. O filme documentário estreou em junho de 2019 na $14^{\circ}$ Mostra de Cinema de Ouro Preto - CINEOP sendo depois exibido e premiado no
As exposições itinerantes promovidas pelo Instituto Moreira Sales - IMS - com acervos familiares dos fotógrafos originários da cidade de Diamantina - Minas Gerais, Assis Horta (1918-2018), e depois de seu mentor, Chichico Alkmim (1886 - 1978) confirmam a importância de arquivar, preservar e difundir acervos fotográficos familiares advindos das famílias de fotógrafos profissionais ou não. Há uma infinidade de acervos familiares ou ainda acervos institucionais ainda não pesquisados, com fotografias amadoras e profissionais, que incluem filmes, fotografias e documentos.

As fotografias reproduzidas nesta edição da Arquivos CMD são inéditas e foram encontradas na pesquisa de acervos familiares do cineasta Aristides Junqueira (1879-1952) para a realização do filme documentário de longa-metragem de minha autoria: Até onde pode chegar um filme de família $(2018)^{1}$. Aristides Junqueira é natural de Ouro Preto, e é considerado um pioneiro do cinema brasileiro como autor de dezenas de filmes silenciosos e sonoros rodados em quase todas as regiões do Brasil e cuja a grande maioria do acervo está perdido.
"Reminiscências", filme de família do cineasta rodado entre 1909 e 1926 é o mote do filme documentário para contar sua biografia. Esta película é considerada o filme brasileiro preservado mais antigo, e é parte do acervo das cinematecas do Museu de Arte Moderna - MAM Rio e da Cinemateca Brasileira, mas só se tornou conhecido publicamente nos anos 1970. O filme documentário combina a exibição do filme de família com documentos, fotografias e depoimentos de netos e bisnetos do cineasta, que o conheceram em vida ou são detentores de acervos e memórias sobre o cineasta, em Belo Horizonte e Rio de Janeiro, trazendo à público informações desconhecidas por pesquisadores do chamado primeiro cinema brasileiro até então.

O conjunto de fotografias reproduzidas a seguir remontam sistematicamente o crescimento dos filhos do cineasta Aristides Junqueira ao longo dos anos até a fase adulta. Esta é uma atitude do cineasta que também aparece na cena filmada em 1909 de "Reminiscências". Nas cartelas originais do filme, o cineasta narra o crescimento dos filhos em comparação às cenas que aparecerão em

Dossiê Renato Ortiz, 70 anos: uma obra e muitos ensinamentos depois..

Arquivos do CMD, Volume 8, N.1. Jan/Jun 2019 
mesmo ano como melhor filme no $19^{\circ}$ Congresso Brasileiro de Sociologia - Sociedade Brasileira de Sociologia. Mais informações: https://umfilmedefamilia.wordpress.c om/-Facebook: @umfilmedefamilia seguida: "Comparemos o desenvolvimento da família, do filhos mais velho (o cineasta), quais as criancinhas de 1909?". Na cartela seguinte, o texto chama atenção para o crescimento do filho Moacyr. Em seguida, o próprio cineasta toca e exibe para a câmera cada um dos seus filhos em fila e destaca seu filho Moacyr.
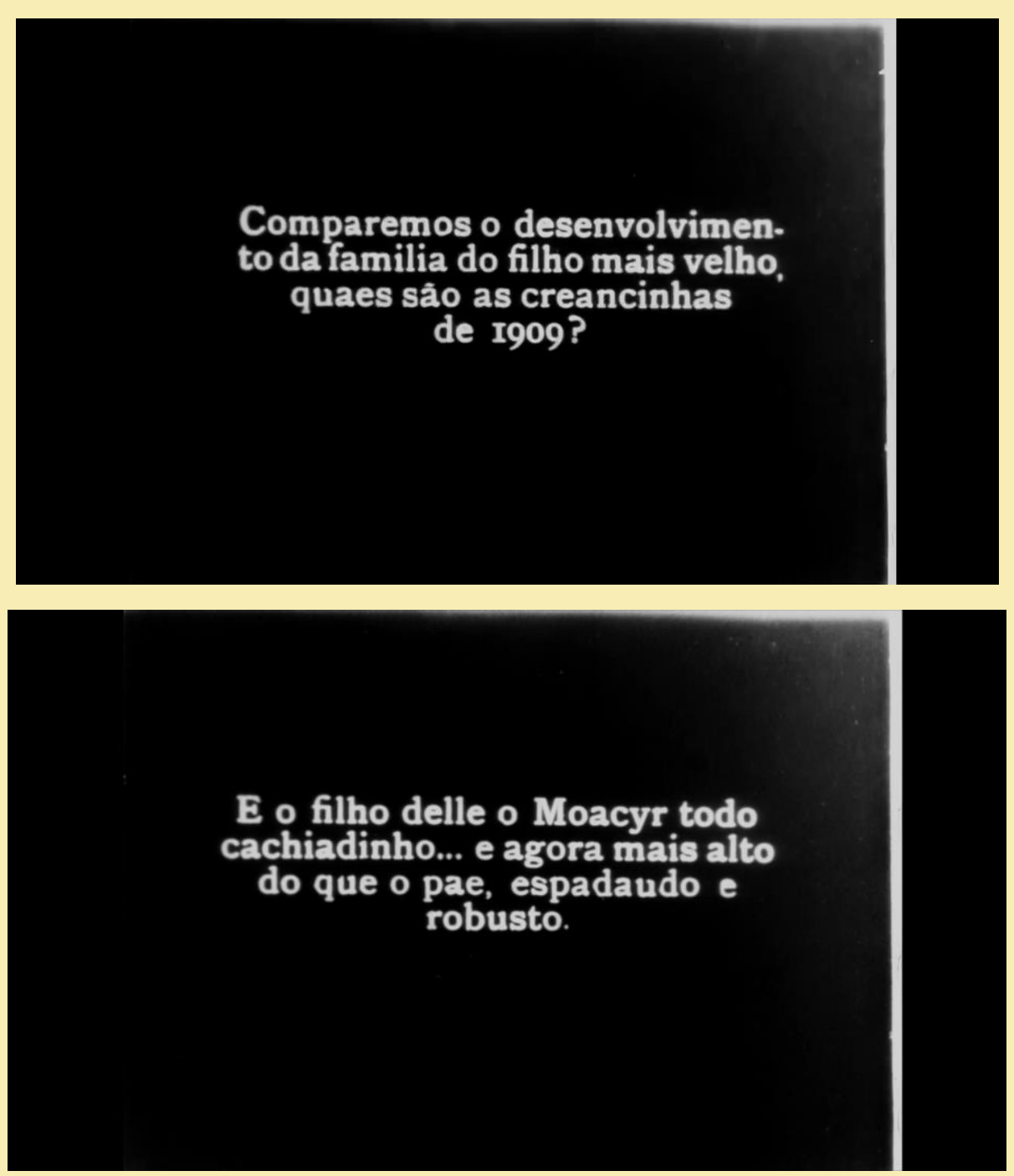

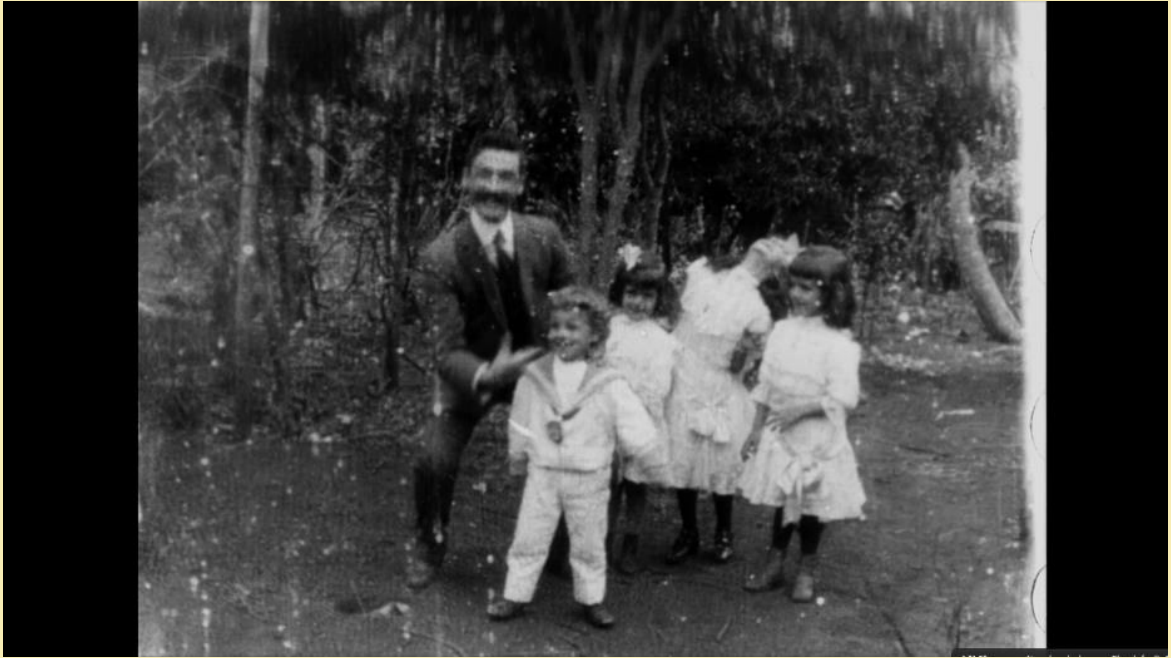

Fotogramas de Reminiscências (1909-26) - Aristides Junqueira Acervo Cinemateca do MAM-Rio - destaque para o filho Moacyr Alvarenga Junqueira no fotograma.

Já na primeira fotografia, os filhos são novamente apresentados em fila, agora mais organizada e posada, expondo-se com vestimentas de um mesmo tom de tecido, talvez feito pelo mesmo rolo de tecido, com faces infantis, com exceção da primeira, a filha mais velha, cujo casamento é registrado em 1925 pelo filme de família "Reminiscências" (1909-26). Ao fundo, a rotunda expõe um cenário escuro, dando a impressão de um ambiente caseiro, e por isso, protegido.

Na segunda fotografia, os filhos são novamente apresentados em fila, com um claro objetivo narrativo de estabelecer uma comparação entre esta foto e a outra mais antiga, e entre os irmãos na mesma foto. Já a rotunda com o cenário ao fundo, já não é mais

Dossiê Renato Ortiz, 70 anos: uma obra e muitos ensinamentos depois..

Arquivos do CMD, Volume8, N.1. Jan/Jun 2019 
caseira, dá a ideia do florescer para uma nova fase da vida. As roupas já não expõe um mesmo tom de tecido, demonstram na verdade, uma individualização das vestimentas e personalidades que contribuem para distinguir uns dos outros.
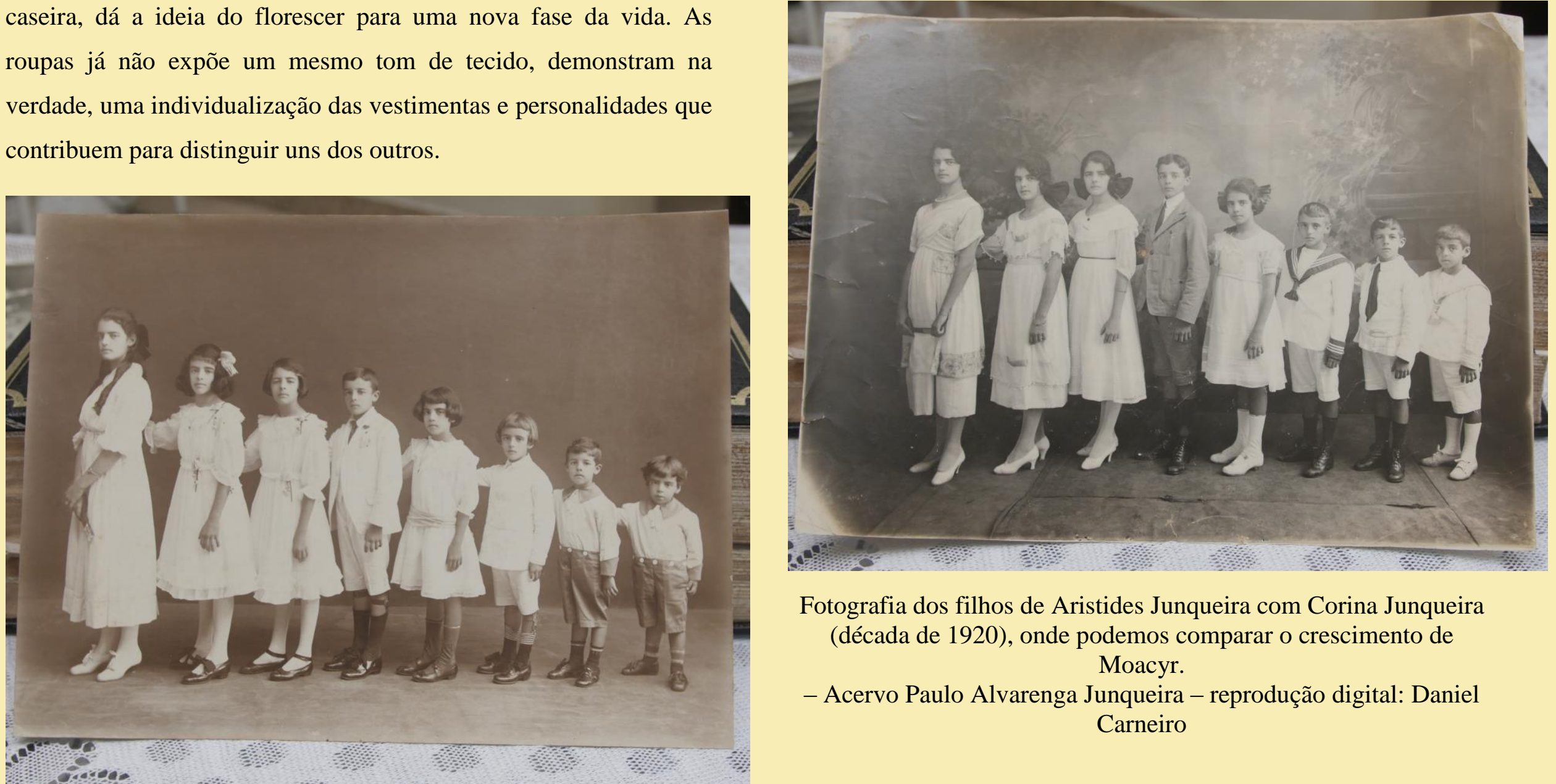

Fotografia dos filhos de Aristides Junqueira com Corina Junqueira (década de 1920), onde podemos comparar o crescimento de Moacyr.

- Acervo Paulo Alvarenga Junqueira - reprodução digital: Daniel Carneiro

Fotografia dos filhos de Aristides Junqueira com Corina Junqueira (década de 1910), sendo Moacyr, o primeiro filho homem da esquerda para direita - Acervo Paulo Alvarenga Junqueira reprodução digital: Daniel Carneiro

Na última foto, passado pelo menos duas décadas, é o próprio cineasta que aparece em primeiro, reconhecendo de costas sua prole. As roupas reforçam a individualização das vestimentas, personalidades e agora, histórias de vida. Até o terno de mesmo tom dos três últimos, se distingue pelo corte de alfaiataria e a posição do lenço nos bolsos do paletó

Dossiê Renato Ortiz, 70 anos: uma obra e muitos ensinamentos depois..

Arquivos do CMD, Volume8, N.1. Jan/Jun 2019 


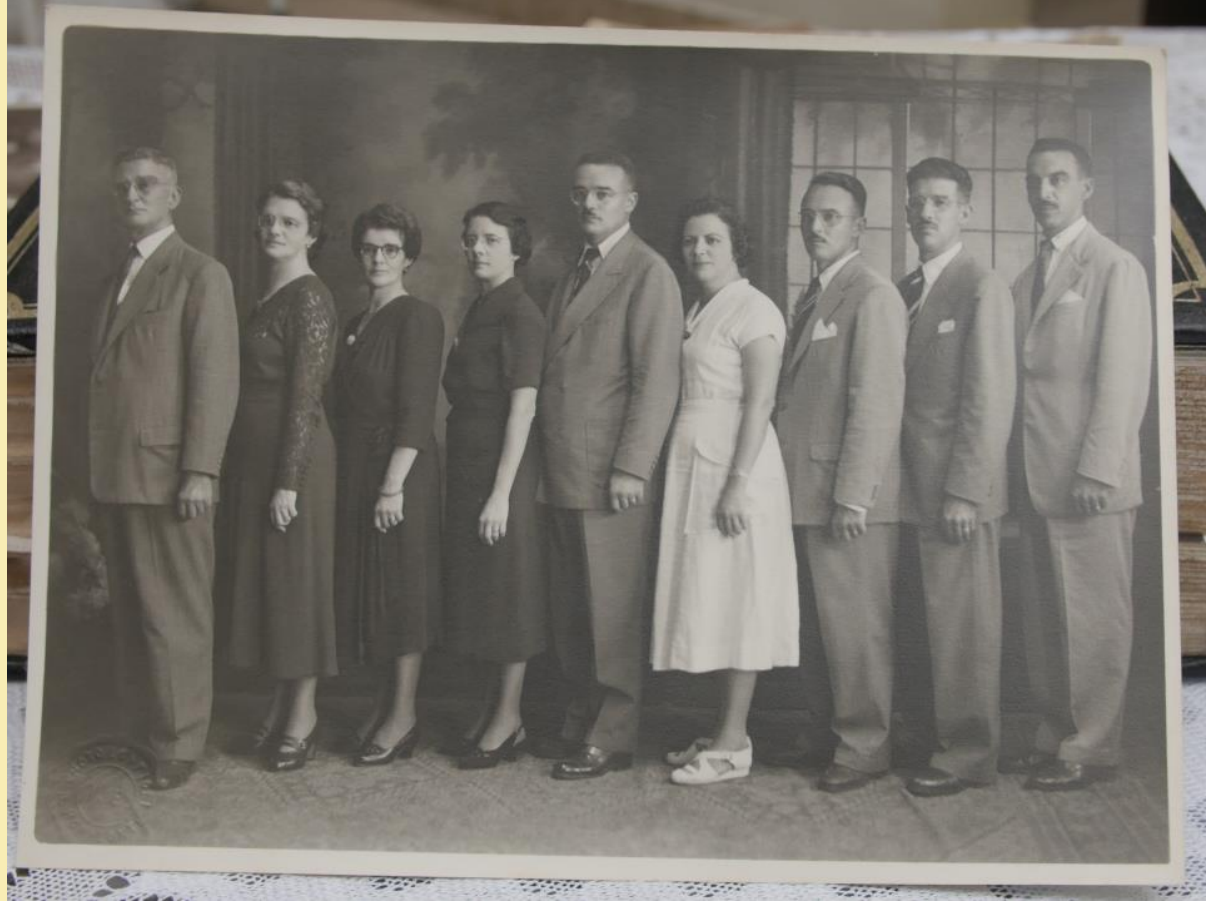

Fotografia dos filhos de Aristides Junqueira com Corina Junqueira (década de 1940)

- Acervo Paulo Alvarenga Junqueira - reprodução digital: Daniel Carneiro

O que guardam as fotografias de família além de memórias? Elas guardam intenções e valores, objetivos e subjetivos, linguagens e corpos que já não existem mais. As fotografias sintetizam as memórias na forma de imagens.

\section{Referências complementares}

Dossiê Renato Ortiz, 70 anos: uma obra e muitos ensinamentos depois...

Arquivos do CMD, Volume8, N.1. Jan/Jun 2019
Assis Horta (1918-2018) - mais informações disponíveis em https://revistazum.com.br/revista-zum-7/o-clique-unico-de-assishortal

Chichico Alkmim (1886-1978) - mais informações disponíveis em: http://brasilianafotografica.bn.br/?p=8890

Aristides Junqueira - mais informações disponíveis em: http://www.historiadocinemabrasileiro.com.br/aristides-junqueira/

Fonseca Junqueira, Rodolfo - Até onde pode chegar um filme de família (2018) - Mais informações:

https://umfilmedefamilia.wordpress.com - Facebook:

@ umfilmedefamilia 